Keywords: polyunsaturated fatty acids; prostate cancer; Mendelian randomisation; polygenic risk score; omega-3 fatty acids; omega-6 fatty acids

\title{
Polyunsaturated fatty acids and prostate cancer risk: a Mendelian randomisation analysis from the PRACTICAL consortium
}

Nikhil K Khankari ${ }^{1}$, Harvey J Murff ${ }^{1}$, Chenjie Zeng ${ }^{1}$, Wanqing Wen ${ }^{1}$, Rosalind A Eeles ${ }^{2,3}$, Douglas F Easton ${ }^{4}$, Zsofia Kote-Jarai ${ }^{2}$, Ali Amin Al Olama ${ }^{4}$, Sara Benlloch ${ }^{4}$, Kenneth Muir ${ }^{5}$, Graham G Giles ${ }^{6,7}$, Fredrik Wiklund ${ }^{8}$, Henrik Gronberg ${ }^{8}$, Christopher A Haiman ${ }^{9}$, Johanna Schleutker ${ }^{10,11}$, Børge G Nordestgaard ${ }^{12}$, Ruth C Travis ${ }^{13}$, Jenny L Donovan ${ }^{14}$, Nora Pashayan ${ }^{4,15}$, Kay-Tee Khaw ${ }^{16}$, Janet L Stanford ${ }^{17,18}$, William J Blot ${ }^{19}$, Stephen N Thibodeau ${ }^{20}$, Christiane Maier ${ }^{21,22}$, Adam S Kibel ${ }^{23,24}$, Cezary Cybulski ${ }^{25}$, Lisa Cannon-Albright ${ }^{26}$, Hermann Brenner ${ }^{27,28}$, Jong Park ${ }^{29}$, Radka Kaneva ${ }^{30}$, Jyotsna Batra ${ }^{31}$, Manuel R Teixeira ${ }^{32,33}$, Hardev Pandha ${ }^{34}$, Wei Zheng ${ }^{*}, 1$ and the PRACTICAL consortium ${ }^{35}$

Background: Prostate cancer is a common cancer worldwide with no established modifiable lifestyle factors to guide prevention. The associations between polyunsaturated fatty acids (PUFAs) and prostate cancer risk have been inconsistent. Using Mendelian randomisation, we evaluated associations between PUFAs and prostate cancer risk.

Methods: We used individual-level data from a consortium of 22721 cases and 23034 controls of European ancestry. Externallyweighted PUFA-specific polygenic risk scores (wPRSs), with explanatory variation ranging from 0.65 to $33.07 \%$, were constructed and used to evaluate associations with prostate cancer risk per one standard deviation (s.d.) increase in genetically-predicted plasma PUFA levels using multivariable-adjusted unconditional logistic regression.

Results: No overall association was observed between the genetically-predicted PUFAs evaluated in this study and prostate cancer risk. However, risk reductions were observed for short-chain PUFAs, linoleic $\left(O R_{L A}=0.95,95 \% C l=0.92,0.98\right)$ and $\alpha$-linolenic acids $\left(O R_{A L A}=0.96,95 \% C l=0.93,0.98\right)$, among men $<62$ years; whereas increased risk was found among men $\geqslant 62$ years for $L A\left(O R_{L A}=1.04,95 \% C l=1.01,1.07\right)$. For long-chain PUFAs (i.e., arachidonic, eicosapentaenoic, and docosapentaenoic acids), increased risks were observed among men $<62$ years $\left(\mathrm{OR}_{\mathrm{AA}}=1.05,95 \% \mathrm{Cl}=1.02,1.08 ; \mathrm{OR} \mathrm{EPA}=1.04,95 \% \mathrm{Cl}=1.01,1.06\right.$; $\left.\mathrm{OR}_{\mathrm{DPA}}=1.05,95 \% \mathrm{Cl}=1.02,1.08\right)$.

Conclusion: Results from this study suggest that circulating $\omega-3$ and $\omega-6$ PUFAs may have a different role in the aetiology of earlyand late-onset prostate cancer.

Prostate cancer is the most common cancer among Caucasian men worldwide (Torre et al, 2015). Identifying modifiable prostate cancer risk factors could help to alleviate the burden of prostate cancer. However, little is known about modifiable factors for this common cancer.
Several previous epidemiologic studies have examined the relation between polyunsaturated fatty acids (PUFAs) and prostate cancer risk (Zock and Katan, 1998; Carayol et al, 2010; Sakai et al, 2012; Alexander et al, 2015). Given the possible role that PUFAs may have in prostate carcinogenesis, with suggested anti-

*Correspondence: Dr W Zheng; E-mail: wei.zheng@vanderbilt.edu

${ }^{35}$ Additional members from the Prostate Cancer Association Group to Investigate Cancer Associated Alterations in the Genome (PRACTICAL) consortium are listed in the Supplementary Material. Information about the consortium can be found at http://practical.ccge.medschl.cam.ac.uk/.

Received 22 April 2016; revised 30 June 2016; accepted 6 July 2016; published online 4 August 2016

(c) 2016 Cancer Research UK. All rights reserved 0007 - 0920/16 
inflammatory effects for $\omega$-3 PUFAs and inflammatory effects for $\omega-6$ PUFAs (Berquin et al, 2011), an examination of these nutritional factors may be warranted. Specifically, metabolism of $\omega-6$ PUFAs via the cyclooxygenase-2 enzyme results in the production of inflammatory mediators including prostaglandin E2 that has been reported to affect prostate carcinogenesis (Sobolewski et al, 2010). Others include the lipoxygenase and cytochrome p450 pathways producing leukotrienes and hydroxyeicosatetraenoic acids, which have also been implicated in cancer development (Panigrahy et al, 2010; Wang and Dubois, 2010). On the contrary, products of $\omega-3$ PUFA metabolism via these same biologic pathways have demonstrated anti-inflammatory properties (Chapkin et al, 2009). However, the association between PUFAs and prostate cancer risk is not supported by a recent meta-analysis summarising prospective studies of long-chain $\omega$-3 PUFA intake and prostate cancer incidence that reported null results for both self-reported dietary intakes and biomarker measures of PUFAs (Alexander et al, 2015). Observational studies of dietary factors and cancer risk are prone to biases, including confounding, selection bias, measurement error, and reverse causation. Measurement error is an important limitation for studies examining diet via food frequency questionnaires. Although biomarker PUFA measurements may provide an objective measure of intake, depending on the biomarker used (i.e., serum $v$ s red blood cell) the time period of exposure will vary (Arab, 2003), and thus an objective PUFA measurement may not represent the relevant aetiologic time period. As a result, reverse causation in studies of prostate cancer and diet (regardless of whether diet was measured via food frequency questionnaire or biomarkers) may be of particular concern, given the slow growth of most prostate tumours and the prospect that men diagnosed with low risk (i.e., low volume and grade) disease may not be treated for several years in accord with current treatment guidelines. Given these potential limitations of observational studies the estimation of an unbiased (potentially causal) association may be difficult.

Mendelian randomisation is based on the principle of random assortment of alleles at conception, and may identify causal risk factors for disease by utilising a number of genetic variants (also known as the genetic instrument) as a proxy for an exposure. Previous genome-wide association studies (GWAS) have identified several variants that together explain a large proportion of variation in PUFA levels, thus making them a potential candidate for Mendelian randomisation analysis.

We sought to identify potentially causal associations between genetically-predicted plasma PUFA levels and risk of developing prostate cancer using case-control data from a large consortium. In our Mendelian randomisation analysis, we examined the main $\omega-3$ and $\omega-6$ PUFAs, including: (1) $\omega-6$ PUFAs: linoleic acid (LA) and arachidonic acid (AA); and (2) $\omega$-3 PUFAs: $\alpha$-linolenic acid (ALA), eicosapentaenoic acid (EPA), docosapentaenoic acid (DPA), and docosahexaenoic acid (DHA).

\section{MATERIALS AND METHODS}

Study population. We used the resources of the Prostate Cancer Association Group to Investigate Cancer Associated Alterations in the Genome (PRACTICAL), a large consortium of prostate cancer genetic association studies (Eeles et al, 2013). In our analysis, we excluded those individuals who were not of European ancestry $(n=1189)$ and all individuals from the Washington University Genetics Study (WUGS) case-only study $(n=944)$ and the Prostate Cancer Mechanisms of Progression and Treatment (PrOMPT) study that had only two controls $(n=168)$. The final analytic data set consisted of 45755 individuals (22 721 cases and 23034 controls).
Instrumental variables. We used results from published GWAS conducted by the Cohorts for Heart and Aging Research in Genomic Epidemiology (CHARGE) consortium examining plasma levels of $\omega-6$ (Guan et al, 2014) and $\omega-3$ (Lemaitre et al, 2011) PUFAs in order to identify genetic variants associated with plasma PUFA levels. We also considered several variants identified from the metabolomics literature; however, many of these singlenucleotide polymorphisms (SNPs) were either the same or in high linkage disequilibrium with those reported in the two CHARGE GWAS. Therefore, in total we identified 23 SNPs associated with any PUFA trait from these two published GWAS. Of these, 14 were associated with the essential PUFAs (i.e., LA, AA, ALA, EPA, DPA, and DHA). Finally, 9 of these 14 SNPs were independent $\left(r^{2}<0.1\right)$, and thus were used in the genetic instrument for the Mendelian randomisation analyses. Please refer to Supplementary Figure 1 for a summary of SNP selection.

For each variant selected, the allele that was associated with increased levels of plasma PUFAs was considered the effect allele, and the summary statistics for these effect alleles were obtained from published PUFA GWAS (Lemaitre et al, 2011; Guan et al, 2014). Two of these selected variants (rs174547 and rs16966952) were associated with multiple PUFAs and, thus, were not exclusive to any particular genetic instrument.

Genotyping and imputation. The PRACTICAL study samples were genotyped using a custom Illumina Infinium array (iCOGS) as part of the Collaborative Oncological Gene-environment Study (COGS), including > 85000 prostate cancer-related SNPs selected from four previous GWAS (UKGPCS, CGEMS, BPC3, and CAPS), fine mapping of known prostate cancer susceptibility regions at the time of custom chip design, and from candidate gene studies examining important biologic pathways (including hormone metabolism, cell cycle, and DNA repair) (Eeles et al, 2013). Standard quality control protocols were followed by excluding individuals with genotyping call rates $<95 \%$, heterozygosity greater than or less than 4.89 standard deviations from the ethnicity-specific mean, duplicates, and relative pairs (Eeles et al, 2013; Al Olama et al, 2014). Single-nucleotide polymorphisms with call rates $<95 \%$ were excluded, as well as those deviating from Hardy-Weinberg Equilibrium in the controls at $P$-value $<1 \times 10^{-7}$ (Eeles et al, 2013; Al Olama et al, 2014). Of the nine SNPs associated with PUFAs included in our analysis, three were directly genotyped (rs780094, rs2236212, and rs174538) and six were imputed (rs3734398, rs3798713, rs1074011, rs174547, rs2727270, and rs1696695) with high quality $\left(r^{2}>0.76\right)$. Singlenucleotide polymorphisms were imputed in two stages; first using SHAPEIT (http://www/shapeit.fr/) by chromosome and chunk, and then data were phased with the haplotypes from 1000 Genomes Phase 3 (March 2012 release) which were then used for imputation using IMPUTE.V2 (https://mathgen.stats.ok.ac.uk/ impute/impute_v2.html) (Eeles et al, 2013; Al Olama et al, 2014).

Weighted-polygenic risk scores. For analyses using individuallevel data, an externally weighted-polygenic risk score (wPRS) was constructed for each PUFA separately using the SNPs associated with that fatty acid. Allele dosage was used for imputed SNPs. Using this information, PUFA-specific wPRSs were constructed per individual where effect alleles were weighted according to their published associations from PUFA GWAS (Lemaitre et al, 2011; Guan et al, 2014), as follows:

$$
\sum_{i=1}^{n} \beta_{i} S N P_{i}
$$

where $\mathrm{SNP}_{i}$ represents the effect allele dosage and $\beta_{i}$ represents the increase in PUFA levels (as a percentage of total plasma fatty acids) for that specific variant, summed across each of the $n$ variants used in the PUFA-specific wPRSs. Thus, the wPRS represents an 
deviation increase for each PUFA-specific wPRS, thus representing a standard deviation increase in percentage of PUFA levels per total plasma fatty acids (Supplementary Table 2).

Assessing pleiotropy. Two data-driven approaches were used to formally assess the impact of genetic pleiotropy on our results using summary statistics. First, we assessed the impact of genetic pleiotropy and potentially invalid instruments using Egger regression (Bowden et al, 2015). This approach assesses the validity of the genetic instrument and provides an estimate of the average pleiotropic effect across genetic instruments used in the instrument (Supplementary Table 2).

Second, given several variants were included in the different PUFA-specific genetic instruments, we conducted a sensitivity analysis to account for this potential pleiotropy. This method also further evaluated the strength of the genetic instruments used in our analysis. Using a weighted regression-based approach, the association $\left(Y_{g}\right)$ between variant $(g)$ and prostate cancer $(Y)$ was regressed on the association $\left(X_{g}\right)$ between that same variant $(g)$ and the PUFA trait of interest $(X)$, weighted by the inverse variance $\left(\sigma_{Y g}^{-2}\right)$ (Burgess et al, 2015; Burgess and Thompson, 2015). This approach accounts for the potential pleiotropy of variants used in each instrument on other PUFA traits. Results from this sensitivity analysis to account for potential pleiotropy and causal associations between PUFA subtypes are presented in Supplementary Table 3.

\section{RESULTS}

In Table 1, we provide a list of PUFA-associated genetic variants and their GWAS-reported results that were used to create the PUFA-specific wPRSs. Each PUFA-specific instrument explanatory variation ranged from $0.65 \%$ (for DHA) to $\sim 33 \%$ (for AA). Because of the large size of the PRACTICAL consortium, the F-statistic for all the genetic variants was large (all F-statistics were $>10$ ), indicating a strong genetic instrument for the PUFA exposures of interest (Stock et al, 2002).

The associations between one standard deviation increase in wPRSs with prostate cancer risk for the majority of PUFA-specific wPRSs were null (Table 2). When stratified by age, modest increases in prostate cancer risk were observed for AA $(\mathrm{OR}=1.05$, $95 \% \mathrm{CI}=1.02,1.08)$, $\mathrm{EPA}(\mathrm{OR}=1.04,95 \% \mathrm{CI}=1.01,1.06)$, and DPA $(\mathrm{OR}=1.05,95 \% \mathrm{CI}=1.02,1.08)$ among men $<62$ years of age; whereas a modest risk reduction was observed for LA $(\mathrm{OR}=0.95,95 \% \mathrm{CI}=0.92,0.98)$ and ALA $(\mathrm{OR}=0.96,95 \%$ $\mathrm{CI}=0.93,0.98)$ among this same age group. No differences were observed when stratified by smoking status (ever $v s$ never smokers), disease status (advanced vs non-advanced prostate cancer), or method of detection (screen-detected $v s$ clinicallydetected prostate cancer). When modeled using the restricted cubic splines, the associations between the wPRS and prostate cancer risk were also null (data not shown). The pooled results for the association between PUFA-specific wPRSs and prostate cancer risk were nearly identical to the summary estimate derived from fixedand random-effects meta-analyses of the wPRSs and prostate cancer risk across studies included in the PRACTICAL consortium (Supplementary Figures 6-11). Furthermore, our results did not change after adjusting for different covariates, including age and physical activity that were found to be associated with the PUFAspecific wPRSs (Supplementary Table 1). We also conducted a Mendelian randomisation analysis via the two-sample method using summary statistics scaled per one standard deviation unit increase (Supplementary Table 2), and the results were nearly identical to those obtained from the individual-level analysis using wPRSs.

The impact of pleiotropic variants on the Mendelian randomisation estimate was assessed using two different approaches, Egger regression and a weighted regression-based method. With the exception of the wPRS for DPA $\left(\beta_{0}=0.01304, P<0.0001\right)$, we did not observe any statistically significant intercepts as an indication of potential pleiotropic effects and an invalid instrument (Supplementary Table 2). We also assessed the impact of pleiotropic variants on other PUFA traits via the weighted regression-based approach and, in general, observed little difference between the unadjusted models and models adjusted for potential pleiotropic effects on other PUFA traits (Supplementary Table 3$)$. A $12 \%$ risk reduction $(95 \% \mathrm{CI}=0.60,1.29)$ for $\mathrm{AA}$ and a $10 \%$ increased risk $(95 \% \mathrm{CI}=0.88,1.36)$ for ALA were indicated after adjusting for the potential pleiotropic effects of the instrument on other PUFA traits; however, the confidence intervals were imprecise.

\section{DISCUSSION}

We examined the association between genetically-predicted plasma PUFA levels (via construction of PUFA-specific wPRSs) using individual-level data and summary statistics for PUFAs in relation to prostate cancer risk. Our findings suggest no overall association between plasma PUFA levels and risk of developing prostate cancer. However, a potential interaction with age $(<62$ vs $\geqslant 62$ years of age) was observed.

Meta-analysis results from previous studies of Caucasian populations reported a null association for studies examining self-reported dietary intakes of long-chain $\omega$-3 PUFAs (summary $\mathrm{RR}=1.00,95 \% \mathrm{CI}=0.93,1.09$ ), and a modest, but not statistically significant, increased risk for studies examining biomarkers (summary $\mathrm{RR}=1.07 ; 95 \% \mathrm{CI}=0.94,1.20$ ) (Alexander et al, 2015). The meta-analysis also suggested prostate cancer risk reductions from studies that examined DPA intake via self-report (summary $\mathrm{RR}=0.92 ; 95 \% \mathrm{CI}=0.71,1.19$ ) and biomarkers (summary $\mathrm{RR}=0.85,95 \% \mathrm{CI}=0.72,0.99$ ). Results from another meta-analysis of prospective studies reported null associations with high intake of ALA in relation to prostate cancer risk (Carayol et al, 2010). Although our results for the overall null association were consistent with findings from previous studies as summarised in the two meta-analyses described above, we found that the association between PUFAs and prostate cancer risk may be modified by age at onset. Stratification by age at onset may have revealed the cumulative effect of PUFAs on prostate cancer risk. Given germline genetic variation will not vary over time, and if we assume that the wPRS is representative of a cumulative lifetime exposure to PUFAs, then it is possible that a higher magnitude of the effect would have been revealed for older men (e.g., increased risk for $\omega-6$ would have been stronger and reduced risk would have been lower for $\omega-3$ PUFAs among older men). However, our results indicate modest increases in risks for LA and modest reduced risks for long-chain $\omega-3$ PUFAs (EPA, DPA, and DHA) among older men $(\geqslant 62$ years of age) relative to younger men ( $<62$ years). It is also possible that prostate cancer cases diagnosed at $<62$ years of age could reflect a more aggressive form of disease. However, when we considered stratification by disease severity the increased risks were not observed. Thus, additional research may be needed to disentangle the effects of screening and the potential for outcome misclassification of aggressive $v s$ indolent prostate cancer cases. For $\omega-6$ PUFAs, a systematic review reported no strong positive association for AA (either dietary or biomarker) in relation to prostate cancer risk (Sakai et al, 2012), nor was an association observed in a meta-analysis of dietary LA intake and prostate cancer risk (Zock and Katan, 1998).

Although our study was sufficiently large to detect associations between PUFAs and prostate cancer incidence, several limitations remain. First, Mendelian randomisation assumes that the genetic 


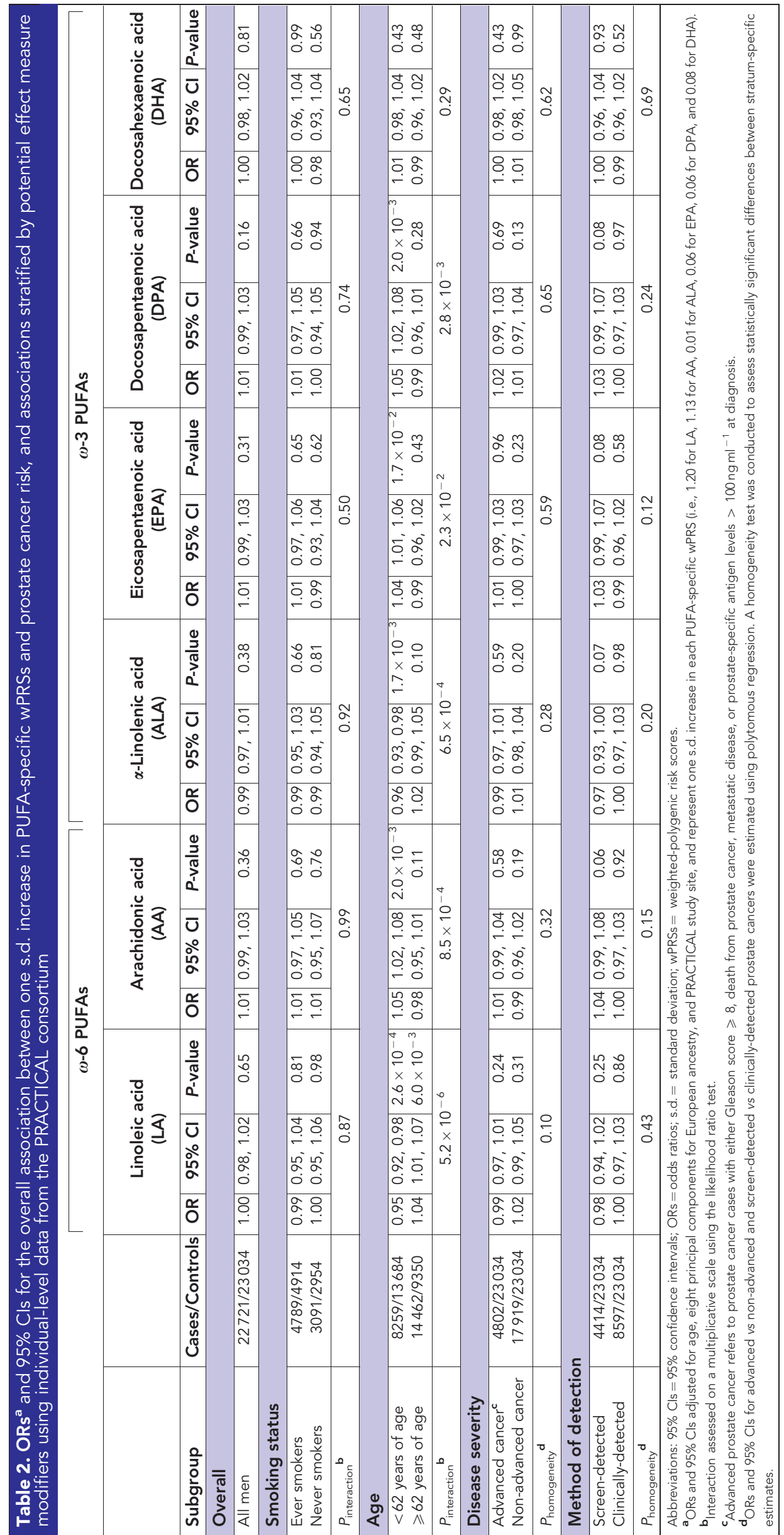


instrument is (1) associated with the exposure; (2) not associated with any confounders of the exposure-outcome association; and (3) independent of the outcome given the exposure and confounders (i.e., the genetic instrument only affects the outcome via the exposure of interest) (Burgess et al, 2015; Burgess and Thompson, 2015). The validity of the Mendelian randomisation estimate hinges on these assumptions. In our study, the F-statistics for all the genetic instruments were large $(>10)$ indicating strong genetic instruments that are associated with the exposure. However, for many of the PUFA-specific instruments the percentage of variation explained was low $(<3 \%)$, and future research investigations should identify additional variants to incorporate into the genetic instruments to further improve the instrument strength. Furthermore, the PUFA-specific genetic instruments were not associated with potential confounders, with the exception of physical activity for DPA and DHA. However, adjustment for physical activity did not alter our conclusions, thus providing additional evidence that the genetic instruments utilised in this analysis are independent of confounders. The only potential concern regarding the validity of the genetic instrument is the possibility of unknown pleiotropic effects, which would violate the aforementioned third assumption. Even though this analysis used several common GWAS-identified variants in the PRS, there are likely additional rare variants that were not included in this analysis and have yet to be discovered. However, even with the inclusion of potential rare variants, the percent variation explained by the genetic instrument may not be vastly improved unless these rare variants are found to have large effects. Further replication by others is required to elucidate the true associations for other PUFAs, including the long-chain $\omega$-3 PUFAs for which antiinflammatory action has been suggested by laboratory studies (Berquin et al, 2011). Although we examined stratification by disease status, the possibility for misclassification of aggressive vs low-risk prostate cancer cases remains. Future advancements in prostate cancer screening, via serum (i.e., prostate health index or Kallikrein protein levels) or urinary (i.e., PCA3 or TMPRSS2-ERG fusion) markers (Cuzick et al, 2014), may help to better separate aggressive prostate cancer from low-risk indolent cases, which may help to potentially reveal the benefits of long-chain $\omega-3$ PUFAs among truly aggressive prostate cancers.

Our analysis has several strengths. First, we conducted analyses using individual-level data, which allowed us to control for potential confounders of the association between the wPRS and prostate cancer risk, including principal components for European ancestry. The individual-level analysis also allowed us to examine effect measure modification by conducting stratified analyses. Second, we conducted our analysis using a large sample of data from the PRACTICAL consortium. Furthermore, we utilised available summary statistics data from this large PRACTICAL consortium and effect estimates from previous PUFA GWAS to conduct a two-sample Mendelian randomisation analysis. Given large sample sizes of these studies and the use of independent variants in each genetic instrument, the Mendelian randomisation estimate from the two-sample approach using summary statistics will be equivalent to the Mendelian randomisation estimate from a one-sample approach (via two-stage least-squares regression) with available genetic and biomarker information (Haycock et al, 2016). Although, we did not observe any substantial pleiotropic effects when we conducted the weighted regression-based method (Burgess et al, 2015; Burgess and Thompson, 2015) nor via Egger regression (Bowden et al, 2015), we are unable to completely rule out the impact of unknown pleiotropic effects that could reduce the validity of the Mendelian randomisation estimate (in particular for DPA, for which the Egger's $P$-value was statistically significant). Finally, the proportion of variation explained by the SNPs included in the genetic instrument for several PUFAs (AA, LA, and DPA) was relatively high compared with other Mendelian randomisation studies examining other traits (Ehret et al, 2011; Ahmad et al, 2015). Thus, the Mendelian randomisation association may reflect the true null association, but requires confirmation by others, using instruments that include additional variants and explain an even higher percentage of variation in fatty acid levels (especially for those PUFAs for which the percentage of variation explained was low).

In conclusion, using data from a large consortium, we report an overall null association between PUFAs (both $\omega-3$ and $\omega-6$ ) and prostate cancer risk. Specifically, we report no association for AA in relation to prostate cancer incidence, for which the strength of the instrument and proportion of variation explained were high. However, increased risks were indicated for men $<62$ years of age for genetically-predicted increases in long-chain $\omega-6$ (AA). Similar increases were observed for long-chain $\omega-3$ PUFAs (EPA and DPA) among this age group, which is contrary to what would be expected, given the hypothesised anti-inflammatory action of longchain $\omega-3$ PUFAs. Future investigations into these different associations by age at onset could help to elucidate the roles of PUFAs in the aetiology of prostate cancer.

ACKNOWLEDGEMENTS

Dr Nikhil K Khankari was supported by NIH grant R25CA160056.

\section{CONFLICT OF INTEREST}

The authors declare no conflict of interest.

\section{REFERENCES}

Ahmad OS, Morris JA, Mujammami M, Forgetta V, Leong A, Li R, Turgeon M, Greenwood CMT, Thanassoulis G, Meigs JB, Sladek R, Richards JB (2015) A Mendelian randomization study of the effect of type-2 diabetes on coronary heart disease. Nat Commun 6: 7060.

Alexander DD, Bassett JK, Weed DL, Barrett EC, Watson H, Harris W (2015) Meta-analysis of long-chain omega-3 polyunsaturated fatty acids (LC $\omega-3$ PUFA) and prostate cancer. Nutr Cancer 67: 543-554.

Arab L (2003) Biomarkers of fat and fatty acid intake. J Nutr 133 (Suppl 3): 925S-932S.

Berquin IM, Edwards IJ, Kridel SJ, Chen YQ (2011) Polyunsaturated fatty acid metabolism in prostate cancer. Cancer Metastasis Rev 30: 295-309.

Bowden J, Davey Smith G, Burgess S (2015) Mendelian randomization with invalid instruments: effect estimation and bias detection through Egger regression. Int J Epidemiol 44: 512-525.

Burgess S, Butterworth A, Thompson SG (2013) Mendelian randomization analysis with multiple genetic variants using summarized data: mendelian randomization using summarized data. Genet Epidemiol 37: 658-665.

Burgess S, Dudbridge F, Thompson SG (2015) Re: 'Multivariable Mendelian randomization: the use of pleiotropic genetic variants to estimate causal effects'. Am J Epidemiol 181: 290-291.

Burgess S, Thompson SG (2015) Multivariable Mendelian randomization: the use of pleiotropic genetic variants to estimate causal effects. Am J Epidemiol 181: 251-260.

Carayol M, Grosclaude P, Delpierre C (2010) Prospective studies of dietary alpha-linolenic acid intake and prostate cancer risk: a meta-analysis. Cancer Causes Control 21: 347-355.

Chapkin RS, Kim W, Lupton JR, McMurray DN (2009) Dietary docosahexaenoic and eicosapentaenoic acid: emerging mediators of inflammation. Prostaglandins Leukot Essent Fatty Acids 81: 187-191.

Cuzick J, Thorat MA, Andriole G, Brawley OW, Brown PH, Culig Z, Eeles RA, Ford LG, Hamdy FC, Holmberg L, Ilic D, Key TJ, Vecchia CL, Lilja H, Marberger M, Meyskens FL, Minasian LM, Parker C, Parnes HL, Perner S, Rittenhouse H, Schalken J, Schmid H-P, Schmitz-Dräger BJ, Schröder FH, Stenzl A, Tombal B, Wilt TJ, Wolk A (2014) Prevention and early detection of prostate cancer. Lancet Oncol 15: e484-e492. 
Desquilbet L, Mariotti F (2010) Dose-response analyses using restricted cubic spline functions in public health research. Stat Med 29: 1037-1057.

Eeles RA, Olama AAA, Benlloch S, Saunders EJ, Leongamornlert DA, Tymrakiewicz M, Ghoussaini M, Luccarini C, Dennis J, Jugurnauth-Little S, Dadaev T, Neal DE, Hamdy FC, Donovan JL, Muir K, Giles GG, Severi G, Wiklund F, Gronberg H, Haiman CA, Schumacher F, Henderson BE, Le Marchand L, Lindstrom S, Kraft P, Hunter DJ, Gapstur S, Chanock SJ, Berndt SI, Albanes D, Andriole G, Schleutker J, Weischer M, Canzian F, Riboli E, Key TJ, Travis RC, Campa D, Ingles SA, John EM, Hayes RB, Pharoah PDP, Pashayan N, Khaw K-T, Stanford JL, Ostrander EA, Signorello LB, Thibodeau SN, Schaid D, Maier C, Vogel W, Kibel AS, Cybulski C, Lubinski J, Cannon-Albright L, Brenner H, Park JY, Kaneva R, Batra J, Spurdle AB, Clements JA, Teixeira MR, Dicks E, Lee A, Dunning AM, Baynes C, Conroy D, Maranian MJ, Ahmed S, Govindasami K, Guy M, Wilkinson RA, Sawyer EJ, Morgan A, Dearnaley DP, Horwich A, Huddart RA, Khoo VS, Parker CC, Van As NJ, Woodhouse CJ, Thompson A, Dudderidge T, Ogden C, Cooper CS, Lophatananon A, Cox A, Southey MC, Hopper JL, English DR, Aly M, Adolfsson J, Xu J, Zheng SL, Yeager M, Kaaks R, Diver WR, Gaudet MM, Stern MC, Corral R, Joshi AD, Shahabi A, Wahlfors T, Tammela TLJ, Auvinen A, Virtamo J, Klarskov P, Nordestgaard BG, Røder MA, Nielsen SF, Bojesen SE, Siddiq A, Fitzgerald LM, Kolb S, Kwon EM, Karyadi DM, Blot WJ, Zheng W, Cai Q, McDonnell SK, Rinckleb AE, Drake B, Colditz G, Wokolorczyk D, Stephenson RA, Teerlink C, Muller H, Rothenbacher D, Sellers TA, Lin H-Y, Slavov C, Mitev V, Lose F, Srinivasan S, Maia S, Paulo P, Lange E, Cooney KA, Antoniou AC, Vincent D, Bacot F, Tessier DC. COGS-Cancer Research UK GWAS-ELLIPSE (part of GAME-ON) Initiative, Australian Prostate Cancer Bioresource, UK Genetic Prostate Cancer Study Collaborators/British Association of Urological Surgeons' Section of Oncology, UK ProtecT (Prostate testing for cancer and Treatment) Study Collaborators, PRACTICAL (Prostate Cancer Association Group to Investigate Cancer-Associated Alterations in the Genome) ConsortiumKote-Jarai Z, Easton DF (2013) Identification of 23 new prostate cancer susceptibility loci using the iCOGS custom genotyping array. Nat Genet 45: 385-391, 391e1-39e2e.

Ehret GB, Munroe PB, Rice KM, Bochud M, Johnson AD, Chasman DI, Smith AV, Tobin MD, Verwoert GC, Hwang S-J, Pihur V, Vollenweider P, O'Reilly PF, Amin N, Bragg-Gresham JL, Teumer A, Glazer NL, Launer L, Hua Zhao J, Aulchenko Y, Heath S, Sõber S, Parsa A, Luan J, Arora P, Dehghan A, Zhang F, Lucas G, Hicks AA, Jackson AU, Peden JF, Tanaka T, Wild SH, Rudan I, Igl W, Milaneschi Y, Parker AN, Fava C, Chambers JC, Fox ER, Kumari M, Jin Go M, van der Harst P, Hong Linda Kao W, Sjögren M, Vinay DG, Alexander M, Tabara Y, Shaw-Hawkins S, Whincup PH, Liu Y, Shi G, Kuusisto J, Tayo B, Seielstad M, Sim X, Hoang Nguyen K-D, Lehtimäki T, Matullo G, Wu Y, Gaunt TR, Charlotte Onland-Moret N, Cooper MN, Platou CGP, Org E, Hardy R, Dahgam S, Palmen J, Vitart V, Braund PS, Kuznetsova T, Uiterwaal CSPM, Adeyemo A, Palmas W, Campbell H, Ludwig B, Tomaszewski M, Tzoulaki I, Palmer ND, Aspelund T, Garcia M, Chang Y-PC, O'Connell JR, Steinle NI, Grobbee DE, Arking DE, Kardia SL, Morrison AC, Hernandez D, Najjar S, McArdle WL, Hadley D, Brown MJ, Connell JM, Hingorani AD, INM Day, Lawlor DA, Beilby JP, Lawrence RW, Clarke R, Hopewell JC, Ongen H, Dreisbach AW Li Y, Hunter Young J, Bis JC, Kähönen M, Viikari J, Adair LS, Lee NR, Chen M-H, Olden M, Pattaro C, Hoffman Bolton JA, Köttgen A, Bergmann S, Mooser V, Chaturvedi N, Frayling TM, Islam M, Jafar TH, Erdmann J, Kulkarni SR, Bornstein SR, Grässler J, Groop L, Voight BF, Kettunen J, Howard P, Taylor A, Guarrera S, Ricceri F, Emilsson V, Plump A, Barroso I, Khaw K-T, Weder AB, Hunt SC, Sun YV, Bergman RN, Collins FS, Bonnycastle LL, Scott LJ, Stringham HM, Peltonen L, Perola M, Vartiainen E, Brand S-M, Staessen JA, Wang TJ, Burton PR, Soler Artigas M, Dong Y, Snieder H, Wang X, Zhu H, Lohman KK, Rudock ME, Heckbert SR, Smith NL, Wiggins KL, Doumatey A, Shriner D, Veldre G, Viigimaa M, Kinra S, Prabhakaran D, Tripathy V, Langefeld CD, Rosengren A, Thelle DS, Maria Corsi A, Singleton A, Forrester T, Hilton G, McKenzie CA, Salako T, Iwai N, Kita Y, Ogihara T, Ohkubo T, Okamura T, Ueshima H, Umemura S, Eyheramendy S, Meitinger T, Wichmann H-E, Shin Cho Y, Kim H-L, Lee J-Y, Scott J, Sehmi JS, Zhang W, Hedblad B, Nilsson P, Davey Smith G, Wong A, Narisu N, Stančáková A, Raffel LJ, Yao J, Kathiresan S, O'Donnell CJ, Schwartz SM, Arfan Ikram M, Longstreth Jr WT, Mosley TH, Seshadri S, Shrine NRG, Wain LV, Morken MA, Swift AJ, Laitinen J, Prokopenko I, Zitting P, Cooper JA, Humphries SE, Danesh J, Rasheed A, Goel A, Hamsten A, Watkins H, Bakker SJL, van Gilst WH, Janipalli CS, Radha Mani K, Yajnik CS, Hofman A, Mattace-Raso FUS, Oostra BA,
Demirkan A, Isaacs A, Rivadeneira F, Lakatta EG, Orru M, Scuteri A, Ala-Korpela M, Kangas AJ, Lyytikäinen L-P, Soininen P, Tukiainen T, Würtz P, Twee-Hee Ong R, Dörr M, Kroemer HK, Völker U, Völzke H, Galan P, Hercberg S, Lathrop M, Zelenika D, Deloukas P, Mangino M, Spector TD, Zhai G, Meschia JF, Nalls MA, Sharma P, Terzic J, Kranthi Kumar MV, Denniff M, Zukowska-Szczechowska E, Wagenknecht LE, Fowkes FG, Charchar FJ, Schwarz PEH, Hayward C, Guo X, Rotimi C, Bots ML, Brand E, Samani NJ, Polasek O, Talmud PJ, Nyberg F, Kuh D, Laan M, Hveem K, Palmer LJ, van der Schouw YT, Casas JP, Mohlke KL, Vineis P, Raitakari O, Ganesh SK, Wong TY, Shyong Tai E, Cooper RS, Laakso M, Rao DC, Harris TB, Morris RW, Dominiczak AF, Kivimaki M, Marmot MG, Miki T, Saleheen D, Chandak GR, Coresh J, Navis G, Salomaa V, Han B-G, Zhu X, Kooner JS, Melander O, Ridker PM, Bandinelli S, Gyllensten UB, Wright AF, Wilson JF, Ferrucci L, Farrall M, Tuomilehto J, Pramstaller PP, Elosua R, Soranzo N, Sijbrands EJG, Altshuler D, Loos RJF, Shuldiner AR, Gieger C, Meneton P, Uitterlinden AG, Wareham NJ, Gudnason V, Rotter JI, Rettig R, Uda M, Strachan DP, Witteman JCM, Hartikainen A-L, Beckmann JS, Boerwinkle E, Vasan RS, Boehnke M, Larson MG, Järvelin M-R, Psaty BM, Abecasis GR, Chakravarti A, Elliott P, van Duijn CM, Newton-Cheh C, Levy D, Caulfield MJ, Johnson T (2011) Genetic variants in novel pathways influence blood pressure and cardiovascular disease risk. Nature 478: 103-109.

Guan W, Steffen BT, Lemaitre RN, Wu JHY, Tanaka T, Manichaikul A, Foy M, Rich SS, Wang L, Nettleton JA, Tang W, Gu X, Bandinelli S, King IB, McKnight B, Psaty BM, Siscovick D, Djousse L, Ida Chen Y-D, Ferrucci L, Fornage M, Mozafarrian D, Tsai MY, Steffen LM (2014) Genome-wide association study of plasma N6 polyunsaturated fatty acids within the cohorts for heart and aging research in genomic epidemiology consortium. Circ Cardiovasc Genet 7: 321-331.

Haycock PC, Burgess S, Wade KH, Bowden J, Relton C, Davey Smith G (2016) Best (but oft-forgotten) practices: the design, analysis, and interpretation of Mendelian randomization studies. Am J Clin Nutr 103: 965-978.

Lemaitre RN, Tanaka T, Tang W, Manichaikul A, Foy M, Kabagambe EK, Nettleton JA, King IB, Weng L-C, Bhattacharya S, Bandinelli S, Bis JC, Rich SS, Jacobs DR, Cherubini A, McKnight B, Liang S, Gu X, Rice K, Laurie CC, Lumley T, Browning BL, Psaty BM, Chen Y-DI, Friedlander Y, Djousse L, Wu JHY, Siscovick DS, Uitterlinden AG, Arnett DK, Ferrucci L, Fornage M, Tsai MY, Mozaffarian D, Steffen LM (2011) Genetic loci associated with plasma phospholipid n-3 fatty acids: a metaanalysis of genome-wide association studies from the CHARGE Consortium. PLoS Genet 7: e1002193.

Al Olama AA, Kote-Jarai Z, Berndt SI, Conti DV, Schumacher F, Han Y, Benlloch S, Hazelett DJ, Wang Z, Saunders E, Leongamornlert D, Lindstrom S, Jugurnauth-Little S, Dadaev T, Tymrakiewicz M, Stram DO, Rand K, Wan P, Stram A, Sheng X, Pooler LC, Park K, Xia L, Tyrer J, Kolonel LN, Le Marchand L, Hoover RN, Machiela MJ, Yeager M, Burdette L, Chung CC, Hutchinson A, Yu K, Goh C, Ahmed M, Govindasami K, Guy M, Tammela TLJ, Auvinen A, Wahlfors T, Schleutker J, Visakorpi T, Leinonen KA, Xu J, Aly M, Donovan J, Travis RC, Key TJ, Siddiq A, Canzian F, Khaw K-T, Takahashi A, Kubo M, Pharoah P, Pashayan N, Weischer M, Nordestgaard BG, Nielsen SF, Klarskov P, Røder MA, Iversen P, Thibodeau SN, McDonnell SK, Schaid DJ, Stanford JL, Kolb S, Holt S, Knudsen B, Coll AH, Gapstur SM, Diver WR, Stevens VL, Maier C, Luedeke M, Herkommer K, Rinckleb AE, Strom SS, Pettaway C, Yeboah ED, Tettey Y, Biritwum RB, Adjei AA, Tay E, Truelove A, Niwa S, Chokkalingam AP, Cannon-Albright L, Cybulski C, Wokołorczyk D, Kluźniak W, Park J, Sellers T, Lin H-Y, Isaacs WB, Partin AW, Brenner H, Dieffenbach AK, Stegmaier C, Chen C, Giovannucci EL, Ma J, Stampfer M, Penney KL, Mucci L, John EM, Ingles SA, Kittles RA, Murphy AB, Pandha H, Michael A, Kierzek AM, Blot W, Signorello LB, Zheng W, Albanes D, Virtamo J, Weinstein S, Nemesure B, Carpten J, Leske C, Wu S-Y, Hennis A, Kibel AS, Rybicki BA, Neslund-Dudas C, Hsing AW, Chu L, Goodman PJ, Klein EA, Zheng SL, Batra J, Clements J, Spurdle A, Teixeira MR, Paulo P, Maia S, Slavov C, Kaneva R, Mitev V, Witte JS, Casey G, Gillanders EM, Seminara D, Riboli E, Hamdy FC, Coetzee GA, Li Q, Freedman ML, Hunter DJ, Muir K, Gronberg H, Neal DE, Southey M, Giles GG, Severi G. Breast and Prostate Cancer Cohort Consortium (BPC3), PRACTICAL (Prostate Cancer Association Group to Investigate Cancer-Associated Alterations in the Genome) Consortium, COGS (Collaborative Oncological Gene-environment Study) Consortium, GAME-ON/ELLIPSE ConsortiumCook MB, Nakagawa H, Wiklund F, Kraft P, Chanock SJ, Henderson BE, Easton DF, Eeles RA, 
Haiman CA (2014) A meta-analysis of 87,040 individuals identifies 23 new susceptibility loci for prostate cancer. Nat Genet 46: 1103-1109.

Panigrahy D, Kaipainen A, Greene ER, Huang S (2010) Cytochrome P450-derived eicosanoids: the neglected pathway in cancer. Cancer Metastasis Rev 29: 723-735.

Sakai M, Kakutani S, Horikawa C, Tokuda H, Kawashima H, Shibata H, Okubo H, Sasaki S (2012) Arachidonic acid and cancer risk: a systematic review of observational studies. BMC Cancer 12: 606-2407-12-606.

Sobolewski C, Cerella C, Dicato M, Ghibelli L, Diederich M (2010) The role of cyclooxygenase-2 in cell proliferation and cell death in human malignancies. Int J Cell Biol 2010: 215158.

Stock JH, Wright JH, Yogo M (2002) A survey of weak instruments and weak identification in generalized method of moments. J Bus Econ Stat 20: 518.
Torre LA, Bray F, Siegel RL, Ferlay J, Lortet-Tieulent J, Jemal A (2015) Global cancer statistics, 2012. CA Cancer J Clin 65: 87-108.

Wang D, Dubois RN (2010) Eicosanoids and cancer. Nat Rev 10: 181-193.

Zock PL, Katan MB (1998) Linoleic acid intake and cancer risk: a review and meta-analysis. Am J Clin Nutr 68: 142-153.

This work is published under the standard license to publish agreement. After 12 months the work will become freely available and the license terms will switch to a Creative Commons AttributionNonCommercial-Share Alike 4.0 Unported License.

${ }^{1}$ Division of Epidemiology, Department of Medicine, Vanderbilt Epidemiology Center, Vanderbilt-Ingram Cancer Center, Vanderbilt University School of Medicine, Nashville, TN 37203, USA; ${ }^{2}$ The Institute of Cancer Research, 15 Cotswold Road, Sutton, London SM2 5NG, UK; ${ }^{3}$ Royal Marsden NHS Foundation Trust, Fulham Road, London SW3 6JJ, UK; ${ }^{4}$ Strangeways Research Laboratory, Department of Public Health and Primary Care, Centre for Cancer Genetic Epidemiology, University of Cambridge, 2 Worts' Causeway, Cambridge CB1 8RN, UK; ${ }^{5}$ Institute of Population Health, University of Warwick, Coventry CV4 7AL, UK; ${ }^{6}$ Cancer Epidemiology Centre, Cancer Council Victoria, 615 St Kilda Road, Melbourne, Victoria 3004, Australia; ${ }^{7}$ Centre for Epidemiology and Biostatistics, Melbourne School of Population and Global Health, The University of Melbourne, Melbourne, Victoria 3010, Australia; ${ }^{8}$ Department of Medical Epidemiology and Biostatistics, Karolinska Institute, Stockholm 171 77, Sweden; ${ }^{9}$ Department of Preventive Medicine, Keck School of Medicine, University of Southern California/Norris Comprehensive Cancer Center, Los Angeles, CA 90089, USA; ${ }^{10}$ Department of Medical Biochemistry and Genetics, University of Turku, Turku 20014, Finland; ${ }^{11}$ Institute of Biomedical Technology/BioMediTech, University of Tampere and FimLab Laboratories, Kalevantie 4, Tampere 33014, Finland; ${ }^{12}$ Department of Clinical Biochemistry, Herlev Hospital, Copenhagen University Hospital, Herlev Ringvej 75, Herlev 2730, Denmark; ${ }^{13}$ Cancer Epidemiology, Nuffield Department of Population Health University of Oxford, Oxford OX3 7LF, UK; ${ }^{14}$ School of Social and Community Medicine, University of Bristol, Canynge Hall, 39 Whatley Road, Bristol BS8 2PS, UK; ${ }^{15}$ Department of Applied Health Research, University College London, 1-19 Torrington Place, London WC1E 7HB, UK; ${ }^{16}$ Cambridge Institute of Public Health, University of Cambridge, Forvie Site, Robinson Way, Cambridge CB2 OSR, UK; ${ }^{17}$ Division of Public Health Sciences, Fred Hutchinson Cancer Research Center, Seattle, WA 98109, USA; ${ }^{18}$ Department of Epidemiology, School of Public Health, University of Washington, Seattle, WA 98195, USA; ${ }^{19}$ International Epidemiology Institute, 1455 Research Boulevard, Suite 550, Rockville, MD 20850, USA; ${ }^{20}$ Department of Laboratory Medicine and Pathology, Mayo Clinic, Rochester, MN 55905, USA; ${ }^{21}$ Institute of Human Genetics, University Hospital Ulm, Albert-Einstein-Allee 11, Ulm 89081, Germany; ${ }^{22}$ Department of Urology, University Hospital Ulm, Albert-Einstein-Allee 11, Ulm 89081, Germany; ${ }^{23}$ Division of Urology, Brigham and Women's Hospital/ Dana-Farber Cancer Institute, 45 Francis Street-ASB II-3, Boston, MA 02115, USA; ${ }^{24}$ Washington University, 660 S. Euclid Avenue, St Louis, MO 63110, USA; ${ }^{25}$ Department of Genetics and Pathology, International Hereditary Cancer Center, Pomeranian Medical University, Rybacka 1, Szczecin, Poland; ${ }^{26}$ Division of Genetic Epidemiology, Department of Medicine, University of Utah School of Medicine, Salt Lake City, UT 84108, USA; ${ }^{27}$ Division of Clinical Epidemiology and Aging Research, Division of Preventive Oncology, German Cancer Research Center, Heidelberg 69120, Germany; ${ }^{28}$ German Cancer Consortium (DKTK), German Cancer Research Center (DKFZ), Heidelberg 69120, Germany; ${ }^{29}$ Division of Cancer Prevention and Control, H. Lee Moffitt Cancer Center, 12902 Magnolia Drive, Tampa, FL 33612, USA; ${ }^{30}$ Department of Medical Chemistry and Biochemistry, Molecular Medicine Center, Medical University-Sofia, 2 Zdrave Street, 1431 Sofia, Bulgaria; ${ }^{31}$ Australian Prostate Cancer Research Centre-Queensland, Institute of Health and Biomedical Innovation and Schools of Life Science and Public Health, Queensland University of Technology, Brisbane, Queensland 4102, Australia; ${ }^{32}$ Department of Genetics, Portuguese Oncology Institute, Porto, Portugal; ${ }^{33}$ Biomedical Sciences Institute (ICBAS), Porto University, 4200-072 Porto, Portugal and ${ }^{34}$ Department of Clinical and Experimental Medicine, Targeted Cancer Therapy, The University of Surrey, Guildford, Surrey GU2 7XH, UK

Supplementary Information accompanies this paper on British Journal of Cancer website (http://www.nature.com/bjc) 